\section{China's policies on stem cell research: an opportunity for international collaborations}

\author{
Xi Jin, Lin Zheng, Ruo-heng Zheng and You-ming Li
}

The Science \& Society articles by Richard O. Hynes (US policies on human embryonic stem cells. Nature Rev. Mol. Cell Biol. 9, 993$997(2008))^{1}$ and Robin Lovell-Badge (The regulation of human embryo and stem-cell research in the United Kingdom. Nature Rev. Mol. Cell Biol. 9, 998-1003 (2008)) $)^{2}$ discuss the policies on human embryonic stem (ES) cell research in the United States and the United Kingdom, respectively. As China is the largest developing country with a population of over 1.3 billion, a brief description of the regulation of stem cell research in this country would provide a better picture of the worldwide progress of this field.

Whereas UK and US policies have been frequently amended, stem cell research in China is regulated by only one guideline, which was jointly issued by the Ministry of Science and Technology and the Ministry of Health in December 2003 (see the China Stem Cell website (in Chinese); for the proposal in English, see REF. 3). As yet there have been no amendments to this guideline.

According to this guideline, each local institution has a review committee of specialists, whose expertise ranges from biology, medicine, law, sociology and ethics. These committees are directly responsible for the authorization and surveillance of human ES cell research, and are therefore similar to the Institutional Review Boards in the United States ${ }^{1}$. However, there are no clear guidelines on the criteria for declaring an institution eligible for performing human ES cell research, other than that it must have a qualified review committee. Therefore, this kind of research is much easier and more widespread in China than in other countries.

According to the guideline, reproductive cloning, the transfer of an embryo into the uterus of a woman or animal and the generation of chimeric human embryos are prohibited (the generation of chimeric human embryos is now allowed under the new Human Fertilisation and Embryology Bill in the United Kingdom²). Human therapeutic cloning is allowed, but the in vitro development of the embryos cannot exceed 14 days. Moreover, human ES cells can only be derived from gametes or embryos at the blastula stage that are left over from in vitro fertilization treatments or are voluntarily donated (from aborted fetuses), and from blastula stage embryos that are created by somatic cell nuclear transfer. As in the United Kingdom, the use of transgenic human embryos is allowed. Unlike the United States, where National Institutes of Health funding is restricted only to a few approved cell lines, there is no limitation on which human ES cell lines can be used. Finally, the privacy of donors and patients involved in stem cell research should be protected and informed written consent should be obtained.

Stem cell research has boomed in China in recent years, with 744 articles on stem cells published between 1998 and 2008, ranking tenth in the list of all publications. Papers and total citation numbers increase every year. However, the quality of research is relatively low, probably owing to the lack of central regulation. The average citation number for a stem cell article from a research group in the United Kingdom is 15.30, 11.37 from the United States, 9.53 from Japan and 8.36 from Germany, but only 3.45 from China (data calculated from ISI Web of Knowledge). Therefore, it is important for China to seek international cooperation. The huge Chinese population and the policies that allow abortion and the isolation of stem cells from aborted fetuses could together provide fruitful sources for the isolation of human ES cells. In addition, the Chinese Government has recently invested additional funding in this area of research, and pilot trials on stem cell-based therapy have since been done ${ }^{4}$. China now lacks stem cell specialists to improve the quality of this research, but international collaboration might solve this problem.

$X i$ Jin and You-ming Li are at the Digestive Department and Lin Zheng is at the Infectious Disease Department of the First Affiliated Hospital, Medical School,

Zhejiang University, 79 Oingchun Road, Hangzhou, Zhejiang 310003, China.

Ruo-heng Zheng is at the Reproductive Department, the Red-Cross Hospital of Hangzhou, 208 Huan Cheng Dong Road, Zhejiang 310003, China.

Correspondence to Y.L. e-mail:jxfl007@hotmail.com doi:1038/nrm2528-c1

Hynes, R. O. US policies on human embryonic stem cells. Nature Rev. Mol. Cell Biol. 9, 993-997 (2008). Lovell-Badge, R. The regulation of human embryo and stem-cell research in the United Kingdom. Nature Rev. Mol. Cell Biol. 9, 998-1003 (2008).

3. Ethics Committee of the Chinese National Human Genome Center at Shanghai. Ethical guidelines for human embryonic stem cell research. Kennedy Inst. Ethics J. 14, 47-54 (2004).

4. Salter, B., Cooper, M. \& Dickins, A. China and the global stem cell bioeconomy: an emerging political strategy? Regen. Med. 1, 671-683 (2006). 